\section{Evaluation of misfit and stress distribution in implant-retained prosthesis obtained by different methods}

Bruna Santos Honório Tonin (D1, Raniel Fernandes Peixoto (D2, Jing Fu(D)3, Bruna Neves de Freitas (D)1, Maria da Gloria Chiarello de Mattos (D), Ana Paula Macedo (D) 1.

This study evaluated the vertical misfit, passivity, and stress distribution after tightening the screws of different prosthesis. Two implants were used to simulate the rehabilitation of partially edentulous mandible space from the second premolar to the second molar. 40 three-element screw-retained fixed dental prosthesis with distal cantilever were fabricated and divided into four groups according to the method of production of framework $(n=10): G 1=$ conventional casting one-piece framework, $\mathrm{G} 2=$ conventional casting sectioned and laser welding, G3 = conventional casting sectioned and tungsten inert gas (TIG) welding and $\mathrm{G} 4=$ framework obtained by CAD/CAM (computer-aided design/computer-aided manufacturing) system. The vertical misfits (both screws tightened) and the passive fit (one screw tightened) were measured under a comparator optical microscope. The data was submitted to Shapiro-Wilk test to enable comparison with ANOVA followed by Tukey with Bonferroni adjust ( $\alpha=.05$ ). The qualitative analysis of the stress distribution was performed by the photoelastic method. The vertical misfit (both screws tightened) of the $\mathrm{G} 2(24 \mu \mathrm{m})$ and $\mathrm{G} 3(27 \mu \mathrm{m})$ were significantly higher than $\mathrm{G} 4(10 \mu \mathrm{m})(p=0,006)$. The passive fit (for the non-tightened) of the $\mathrm{G} 1(64$ $\mu \mathrm{m})$ and $\mathrm{G} 3(61 \mu \mathrm{m})$ were significantly higher than the $\mathrm{G} 4(32 \mu \mathrm{m})(p=0,009)$. G1 showed high stress between the implants in the photoelastic analysis and G4 presented lower stress. In conclusion, CAD/CAM method results in less vertical misfit, more passivity, and consequently better stress distribution to the bone.
${ }^{1}$ Department of Dental Materials and Prosthesis, School of Dentistry of Ribeirão Preto, University of São Paulo, Ribeirão Preto, SP, Brazil

${ }^{2}$ Department of Restorative Dentistry, Faculty of Pharmacy, Dentistry and Nursing, Federal University of Ceará, Fortaleza, CE, Brazil

${ }^{3}$ Department of Prosthodontics the Affiliated Hospital of Qingdao University, School of Dentistry, Qindao, China
Correspondence: Bruna Santos Honório Tonin School of Dentistry of Ribeirão Preto Department of Dental Materials and Prosthesis, University of São Paulo, Ribeirão Preto, SP, Brazil Av. do Café - Subsetor Oeste - 11 (N-11), Ribeirão Preto - SP, 14040-904

E-mail brunatonin@gmail.com ; +55 1699248 7778

Key Words: Dental implants, cad-cam prosthetic misfit, stress distribuition

\title{
Introduction
}

Posterior mandible regions may present insufficient bone volume to place standard-length implant and some augmentation procedures are associated with additional surgical intervention, cost, time and patient morbidity $(1,2)$. Implant-retained fixed partial denture (FPD) with distal cantilever could be a conservative option $(3,4)$ because it would avoid bone graft procedures and reduce the risk of biologic complications, as well as time and costs of the treatment (5).

Despite an implant-retained FPD with distal cantilever may improve the masticatory efficiency $(6,7)$, biologic and mechanical complications could occur such as microleakage, soft tissue irritation, loosening or fracture of the prosthetic screws, or loss of osseointegration (8). Therefore, the achievement of passive fit of the FPD frameworks is necessary to decrease the vertical micro gap and stress concentration, mainly in prosthesis with distal cantilever, which has been associated with stress concentration around the implants during the oral functions $(6,7)$.

Absolute passive fit is difficult to be obtained and there is no consensus in the literature on the exact level of misfit considered clinically acceptable in implant frameworks (8). Previous studies described the framework presents passive fit when values between $10-150 \mu \mathrm{m}$ are observed $(9,10)$ Some procedures in the one-piece frameworks can be made, such as sectioning and welding, to improve the adaptation and neutralize the distortions in the frameworks caused by conventional casting (11-14).

Laser welding has been introduced to dental laboratory procedures as an alternative method to soldering, brazing, or TIG welding (15). Laser welding produces concentrated energy in a very short operating time, thus generating less distortion, making it possible to join very thin parts. However, the relatively limited penetration depth of the laser beam and the complexity of selecting the necessary parameters require specific training of the dental technician (16). Moreover, studies have described 
variable resistance results about laser welding $(16,17)$. The tungsten inert gas (TIG) method has been associated with good flexural strength, corrosion resistance and even with values of resistance and adaptation superior to laser welding for different metal alloys $(11,17)$.

Computer-aided design/computer-aided manufacturing (CAD/CAM) method has provided significant improvements in the marginal adaption of frameworks compared to traditional laboratory procedures, including waxing, investing, and casting $(18,19)$. However, this technique is mainly used to fabricate metal frameworks that can also be associated with technical problems like distortion, especially after the burn out to apply the ceramic on metal (20).

The passivity can be evaluated using the one-screw tightening test (21). In this test, one screw is completely tightened and the misfit between the cylinder of the framework and the abutment are measurements on both tightened and non-tightened teeth. Differently, the vertical misfit is evaluated when all the screws are tightened and the measurement is also made between the framework and the abutment. In the vertical discrepancies, the stress around the implant is high and it can be confirmed using the photoelastic stress analysis that uses the optical effect double refraction of mechanically loaded transparent resins for analyzing stress (22).

The purposes of this study were to evaluate the passivity, vertical misfit and stress distribution of implant-retained FPDs with distal cantilever. The work hypothesis was that the different methods to obtain the frameworks would present no significant differences in the passivity, vertical misfit and stress distribution after screw tightening performed by the photoelastic analysis.

\section{Materials and methods}

Manufacture of master model

A polymethylmethacrylate master model (Plexiglas ${ }^{\circledR}$, Altuglas International, Philadelphia, USA) was prepared in a rectangular block format $(50 \times 30 \times 15 \mathrm{~mm})$. From the height posterior region of model was removed $4 \mathrm{~mm}$ to simulate a resorption of the posterior region of mandible $(23,24)$. Two analogs of the external hexagon implant (Neodent, Curitiba, PR, Brazil) corresponding to the second premolar and first molar, and replica of the first premolar made with bisacryl resin (Protemp 4, 3M ESPE, Seefeld, Germany) were placed into the master model using a parallelometer, and fixed cyanoacrylate adhesive glue (Super Bonder, Loctite Brazil Ltda, Itapevi, SP, Brazil). Prefabricated abutments (Mini conical abutment SF $4.1 \times 1.0 \mathrm{~mm}$, Neodent) were screwed on implant analogues with a $20 \mathrm{~N} . \mathrm{cm}$ insertion torque following the manufacturer's guidelines.

\section{FPDs cantilever manufacture}

The 3-unit implant-retained FPD with distal cantilever was waxed-up on the master model and the contouring of a pattern in wax was impressed (Silicone Polglass, Ribeirao Preto, SP, Brazil) for the FPDs standardization in all groups. The FDP waxing-up was reduced in $2 \mathrm{~mm}$ to obtain the frameworks and another silicone mold was made. Thirty waxed-up frameworks were obtained, respectively, in polyurethane models (as described in the next item). 10 frameworks were cast in one-piece (Group 1) and 20 were straight sectioned (by a sharp stainless blade of $0.5 \mathrm{~mm}$ ) between the second pre-molar and the first molar to be welded after the conventional casting, using laser (Group 2) or TIG (Group 3) (Figure 1). The framework waxed-up on the master model was scanned using the D700 scanner (3Shape, Copenhagen, Denmark) and 10 frameworks were machined in Co- $\mathrm{Cr}$ (Group 4) by the Neodent digital milling machine. The frameworks of all groups were obtained with $\mathrm{Co}-\mathrm{Cr}$ alloy.

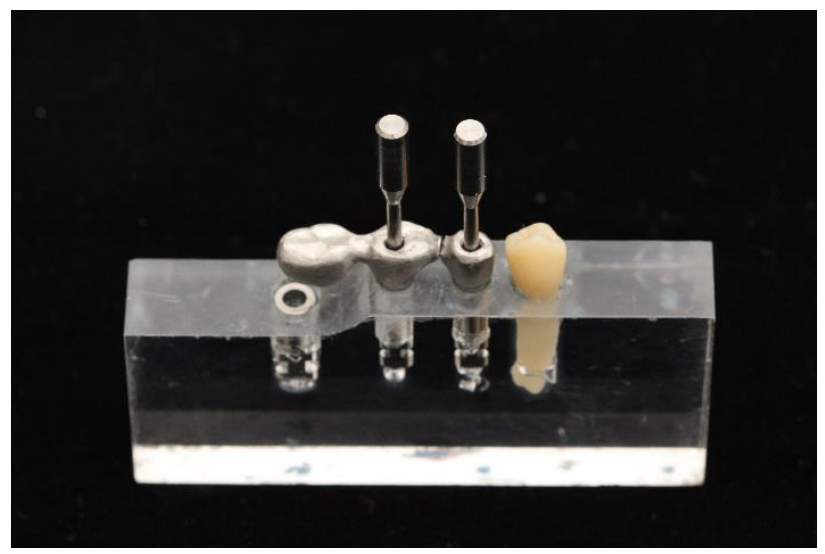

Figure 1. Framework on the master model after casting and before welding procedure. 
The laser welding unit ( $\mathrm{Nd}: Y a g$ laser wave length $1064 \mathrm{~nm}$, Desktop, Dentaurum, Ispringen, Germany) was set at $310 \mathrm{~V}$ and pulse at $9 \mathrm{~ms}$. To minimize distortion, the laser welding was initially performed at diametrically opposed points. After the entire diameter of the section in the framework received welding points applied in a controlled inert gas atmosphere management of argon. The TIG welding was performed by the Plasma Welding Machine (NTY 60k, Kernit, Indaiatuba, SP, Brazil), according to the adapted methodology from the literature (25). In an argon gas environment, the tungsten electrode was positioned 3-6 mm from the infrastructure and set at 4 A power at $0,15 \mathrm{~s}$. As similar to the laser welding method, the TIG welding was executed at diametrically opposed points on the framework section (Figure 2).
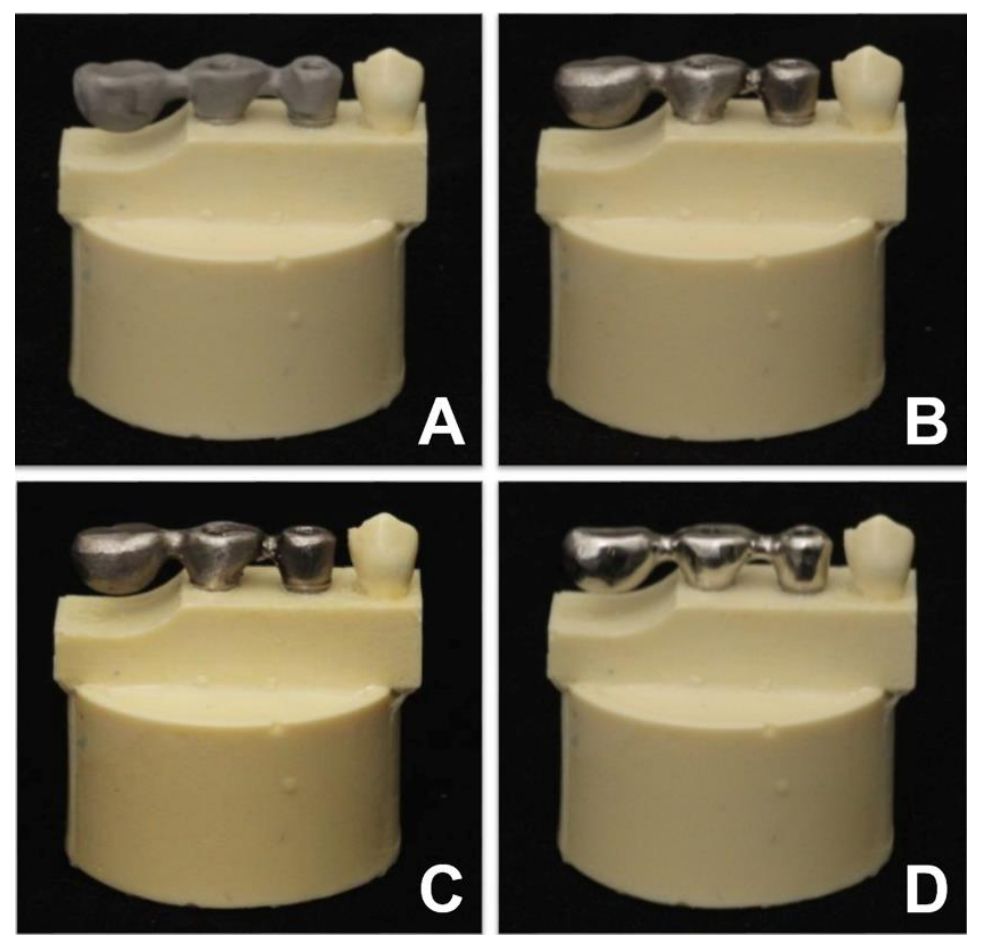

Figure 2. Frameworks before the procedure to apply the ceramic: One-piece -G1 (A), Laser welding - G2 (B), TIG welding - G3 (C) and CAD-CAM - G4

(D).

The opaque (IPS In Line System, Ivoclar, Vivadent, Schaan, Liechtenstein) was applied in two layers on each metallic structure. A silicone impression (Polglass) previously made was used to standardize the aesthetic veneer waxing-up in each specimen. All the steps to pressing of the IPS In Line POM (Ivoclar Vivadent) ceramic for metal infrastructures followed the manufacturer's recommendations. The interproximal contacts between the FPD and the resin tooth were adjusted using a double-sided carbon foils (AccuFilm II; Parkell, NY, USA).

\section{Manufacture of polyurethane models}

The correct transfer of the implant and tooth position to the polyurethane model was made with the aid of impression transfer posts (Neodent) that were screwed to the implant abutments and connected together with acrylic resin (Duralay, Reliance Dental Mfg. Co., Worth, IL, USA). A silicone impression (Polglass) of the master model was performed to allow their correct transfer to the working models. The first premolar replica and implants (Titamax Cortical TI 3,75 x $9 \mathrm{~mm}$, Neodent) with prosthetic components were then positioned in the silicone impression and polyurethane resin (Polyol F16 polyurethane resin and Isocyanate F16-F17 catalyst, Axson Technologies, Eaton Rapids, MI, EUA) was poured. In the end, 40 polyurethane models were manufactured by this method and randomly distributed in four groups $(n=10)$.

\section{Passivity and vertical misfit}

Vertical misfit was measured at 12 points in each crown (3 points per face) with a comparator optical microscope (S8AP0, Leica Microsystems, Wetzlar, Germany) with precision of $1 \mu \mathrm{m}$ and 50x magnification. Measurements were made from abutment to prosthetic cylinder (Figure 3) using the one- 
screw tightening test(21) in two different condition to evaluate the passivity of the FPDs: (1) Molar nontightened and premolar tightened; (2) Molar tightened and premolar non-tightened. Molar and premolar were tightened to evaluate the vertical misfit. The same operator performed all the measurements. The measurements from each side of the specimens were statistically compared and no differences were observed between them $(P>.05)$. As the vertical misfits on the different sides of the same framework were similar, the measurements were considered as averages for the statistical analysis.

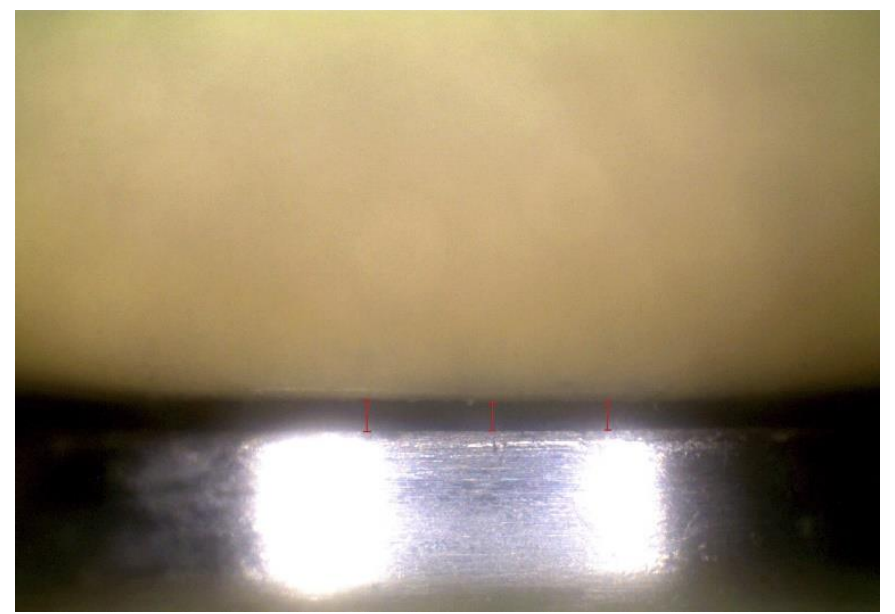

Figure 3. Photomicrography with 3 equidistant points to measurement the vertical misfit.

\section{Photoelastic Analysis}

Three photoelastic models were manufactured using the same silicone impression of the master model (Polglass). The root of the resin teeth was covered with a $0.3 \mathrm{~mm}$ layer of polyether (Impregum Soft, 3M ESPE, Seefeld, Germany) to simulate the periodontal ligament (26). The implants and the tooth were positioned in the silicone model and the photoelastic resin (Araldite GY 279 and Aradur 2963; Huntsman, Everbeg, Belgium) was poured. The set was stored in an air pressure chamber at 60 psi, for 15 minutes to eliminate air molecules. The molds were submitted to photoelastic analysis 72 hours after the pressure exposure. The definitive models were visually evaluated for smoothness and transparency. The best fitted FPD of each group (G1, G2, G3 and G4) was used in each photoelastic model.

Before the tightening torque on the screws, the model was heated to a temperature of $50{ }^{\circ} \mathrm{C}$ for 10 minutes in an incubator (Shaker, Novatecnica Equipamentos, Piracicaba, SP, Brazil) to release the stress induced within the model. Subsequently, the model was kept at room temperature for the same period of time and then checked in the polariscope (G.U.N.T. Garätebau $\mathrm{GmbH}$, Basbuettel, Germany) to confirm the absence of residual stresses. FPDs were screwed with a $10 \mathrm{~N} . c m$ torque (according to the manufacturer's guidelines) and stress distribution around the implants and root were analyzed using the polariscope. The polariscope was adjustment to circular polarization mode, the stress intensity, represented by respective fringe orders - $\mathrm{N}$ (number of fringes) and location were compared subjectively (22). The fringe order 0 is displayed in black, the fringe order 1 is represented by the violet-blue transition and the fringe order 2 is in the red-green transition. The fringe orders 3,4 and 5 correspond to the redgreen transition, as showed in Figure 4. A greater number of fringes indicated greater tension intensity, and the closer fringes are, the greater the stress concentration (27). 


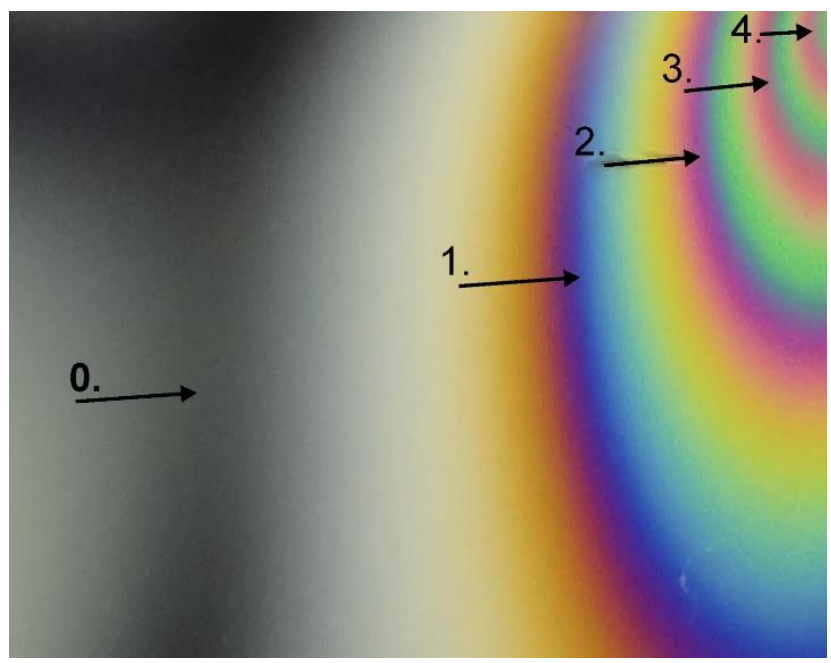

Figure 4. Fringes orders: 0 - black; 1 - violet/blue transition; 2 purple/blue transition; 3 - red/green transition

\section{Statistical analysis}

Shapiro Wilk test was used to check the data normality. ANOVA followed by Tukey with Bonferroni's adjust were used to compare passivity and vertical misfit among groups. For all tests, the significance level was set at 5\%. All results were performed using the IBM SPSS 21.0 software.

\section{Results}

Mean values, standard deviations (SDs) and statistical results for all measurements of and vertical misfits are presented in Table 1. The results found with one of the screws tightened and the micro-gap read on the tightened side showed the lowest values in $G 4$ in comparison to the $G 2(p=0.041)$ and $G 3$ $(p=0.016)$. When the reading was made on the side opposite to the tightened side, G4 exhibited the lowest values of misfit value than $\mathrm{G} 1(p=0.015)$ and $\mathrm{G} 3(\mathrm{p}=0.033)$. The results found with both screws tightened presented the lowest values in $G 4$ in relation to $G 2(p=0.031)$ and $G 3(p=0.006)$.

$\underline{\text { Table 1. Passivity and vertical misfit values (mean } \pm S D, \text { in } \mu \mathrm{m} \text { ) and results of comparison }}$

\begin{tabular}{lccc}
\hline \multirow{2}{*}{ Groups } & \multicolumn{2}{c}{ Passivity } & Vertical Misfit \\
\cline { 2 - 4 } & Tightened side & Opposite side & Both tightened \\
\hline One-piece (G1) & $20.35 \pm 10.10^{\mathrm{AB}}$ & $64.31 \pm 24.81^{\mathrm{A}}$ & $21.73 \pm 13.56^{\mathrm{AB}}$ \\
Laser welding (G2) & $25.38 \pm 11.47^{\mathrm{A}}$ & $45.96 \pm 17.99^{\mathrm{AB}}$ & $24.26 \pm 10.29^{\mathrm{A}}$ \\
TIG welding (G3) & $27.03 \pm 12.13^{\mathrm{A}}$ & $61.36 \pm 27.70^{\mathrm{A}}$ & $27.09 \pm 11.35^{\mathrm{A}}$ \\
CAD/CAM (G4) & $12.53 \pm 4.51^{\mathrm{B}}$ & $31.87 \pm 16.88^{\mathrm{B}}$ & $10.17 \pm 5.47^{\mathrm{B}}$ \\
\hline
\end{tabular}

ANOVA followed by Tukey with Bonferroni's adjust. Different capital (columns) letters for each experimental condition indicate significant differences $(\mathrm{p}<0.05)$.

Qualitative analysis of stress distribution (Figure 5) showed higher stress concentration between the implants of all groups when compared to the apical regions and between tooth and implant. The stress intensity between the implants was even greater in the One-piece group, reaching a fringe order (N) greater than 3 and lower in the CAD/CAM and laser welding groups that showed similar stress intensity (fringe order 2). TIG welding group exhibited fringe order 3. 


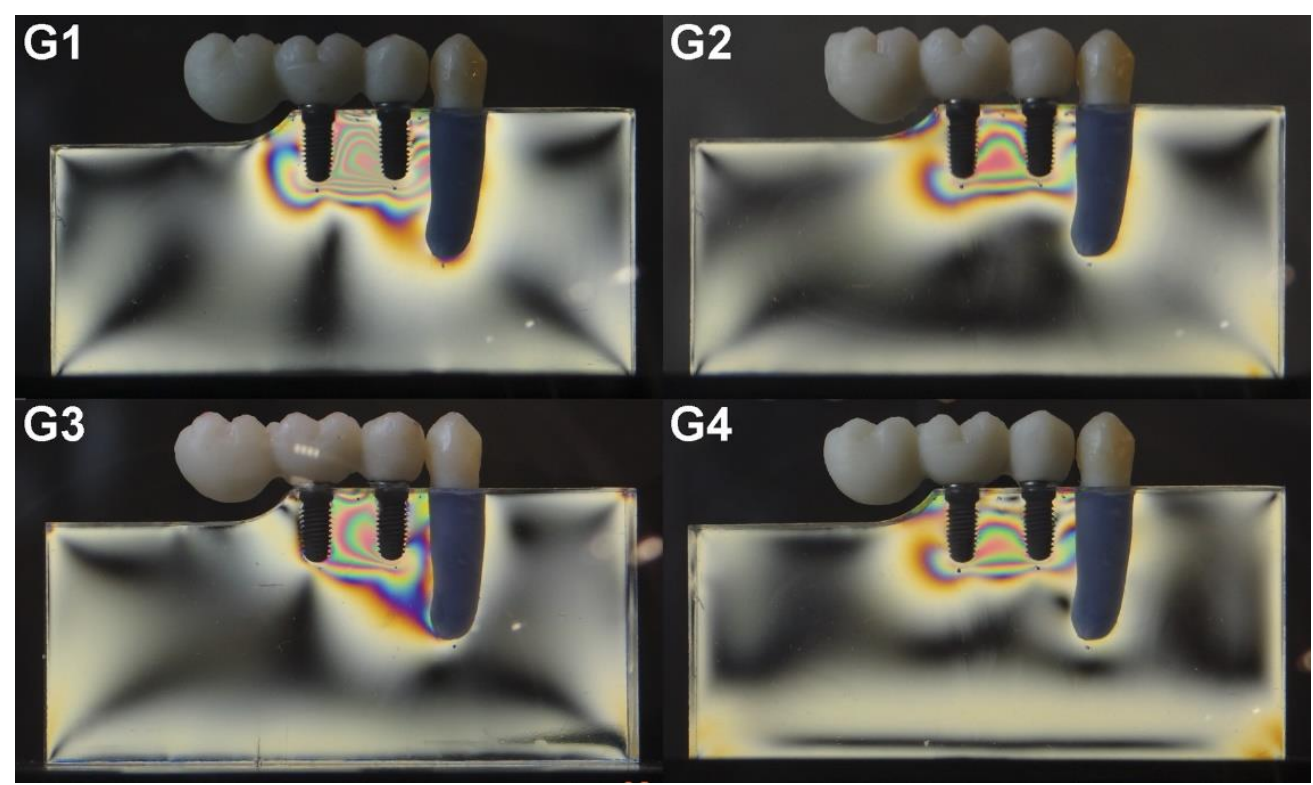

Figure 5. Photoelastic analysis of stress distribution of one-piece (G1), laser welding (G2), TIG welding (G3), and CAD/CAM (G4) frameworks.

\section{Discussion}

Despite all values of vertical misfits showed in the current study are clinically acceptable, as suggested in previous work (28), different stress distribution between the implants can be observed. In this study, the influence of different methods to obtain the frameworks were evaluated. The results reject the work hypothesis since significant differences were found between the groups obtained by conventional casting and CAD/CAM system, and between the welding techniques.

As similar to this study, some works have reported that one-piece casting can be made with a precise fit, while there have care and professional experience necessary to preserve the cervical margin during the finishing and polishing of the frameworks and conserve the bond integrity of the structures $(11,25)$. However, the distortions in the structures can be also caused by conventional casting process and after successive burnouts to apply the opaque and the ceramic veneer (11-14). These procedures are common in laboratory techniques and were simulated in this experiment.

Previous study has claimed that similar values of the passivity and the lower values of the vertical misfit showed by the one-piece group, and by the framework sectioned and welded by TIG may suggest a metal crushing when frameworks sectioning and welding were tightened by both screws (29). As showed in the qualitative analysis by photoelasticity, the metal crushing did not occur in one-piece group; however, high stress was observed between the implants. Major complications occur when stresses exceed the physiological limit of bone, and the resorption process begins (22). Based on these findings, the section and posterior welding are suggested to better distribute the stresses around the implants. Similar results of effective techniques to improve the adaptation of three-unit implantsupported prostheses, as sectioning and welding of the frameworks, also have been detected in other studies $(13,30,31,32)$.

In the present study, the space created during the sectioning in the bar of the framework was not filled with a metal sheet. The TIG welding, even though it is of low intensity, can generate a small contraction in the joint when there is some distance between both fragments without the interposition of any filler metal (33) and it may result in less passivity, as observed in the comparison between the TIG and laser welding groups in the second experimental condition (opposite side).

The TIG welding present more stress between the implant and the tooth and the laser welding exhibited similar stress distribution to the CAD/CAM milled framework. Similar results of passivity were also observed between the laser and CAD/CAM frameworks. Laser welding is the most effective to obtain relatively low values of the marginal misfit when non-noble alloys ( $\mathrm{Ni}-\mathrm{Cr}, \mathrm{Co}-\mathrm{Cr}, \mathrm{cpTI})$ are used resulting in better precision when adapted (34). The Yttrium-aluminum-garnet (YAG) doped with neodymium (ND) crystals is used to emit laser beams ( $N d: Y A G$ laser) to weld dental alloys. As the laser energy can be concentrated in a small area, minimal heating or oxidation effect occur in the area surrounding the welded spot, nonetheless, it presents variable resistance results. In addition, Nd:YAG laser welding offers 
other benefits such as reduced distortion due to a narrow heat affected zone, least contamination with oxide free part, faster process time, corrosion resistant joint, and no galvanic effect due to welding without third material (35). This description may explain the less stress distribution to the bone in the laser group as presented in this study that also used the $\mathrm{Co}-\mathrm{Cr}$ alloy framework.

The advantages of CAD/CAM method result in predictability and reproducibility of the final restoration and improved precision with less time and effort compared to the cast conventional process $(14,25)$. The advent of CAD/CAM technology and the progress of scientific knowledge have allowed best quality in the marginal adjustment of the prosthesis; although, errors inherent to digital work can occur. Thus, surface digitization (intraoral or extraoral), scanners, materials, CAD design, and CAM creation are subject to errors that could affect the final abutment-framework internal and marginal fit $(36,37)$. However, the difference of the obtained accuracy by the methods is considered clinically acceptable (38 39). Thus, during the rehabilitation with digital work is required an adequate treatment planning to standardize procedures, optimize clinical steps, and to obtain a prosthesis with appropriate vertical fit.

In this study, the results of the vertical misfit in one-piece, laser and TIG welding with both screws tightened were small than $30 \mu \mathrm{m}$, a clinically acceptable level and would not cause mechanical and biological complications in long term $(16,40)$. Nonetheless, the CAD/CAM frameworks showed a vertical misfit around $10 \mu \mathrm{m}$. There is no consensus in literature about the vertical misfit clinically acceptable in implant-retained FPDs. Branemark established that a misfit under $10 \mu \mathrm{m}$ can be considered as clinically acceptable (41). Some authors have reported that a vertical misfit of until $150 \mu \mathrm{m}$ does not cause any clinical complications in long term and is therefore clinically acceptable $(9,10)$. Therefore, considering the inaccuracies in the clinical protocol, the vertical misfit found in this study is a reasonable representation of what can occur clinically.

Despite of simplified models has been used in several studies $(22-24,30,32)$ to evaluate the stress distribution of implant-supported prosthesis after the screws tightened, the findings do not present real oral total situation due to variability of the bone matrix and their properties. Nevertheless, the in vitro results may show the possible causes for success or failure of frameworks and contribute to further research (in vitro or in vivo). Although the differences between the clinical situation and photoelastic models, the results recognized with photoelasticity can be appropriate because the stress concentration pattern does not change substancially (42). Different methodologies are used to evaluate biomechanical behavior of implants, among them, the finite element analysis (22). However, the simulated situation around the implant is not a real biological condition, and it does not use real materials then the dimensional alterations from the manufacture procedures are not considered.

A limitation of this study was not applying a load on the FDP to simulate the bite force of dentate adult patients. Similar results of the stress distribution under loading should be expected with the increase of the stress between the implants and high stress around the implant closest to a cantilever unit (43). Once irreversible bone damage is expected when pathologic overloading occurs, causing microfractures at the bone-implant interface, all the techniques to improve the stress generation and passivity of the FDP must be considered. In addition, clinical follow-up studies would be recommended to appraise the long-term survival screw-retained fixed dental prosthesis associated with distal cantilever.In conclusion, within the limitations of this in vitro study, despite the one-piece framework exhibited similar vertical misfit values to the sectioned and welding frameworks (laser and TIG), the one-piece group presented high stress concentration between the dental implants. The CAD/CAM method used to mill the frameworks result less misfit, more passivity and consequently better stress distribution to the bone. Moreover, sectioning and laser welding is a viable alternative to generate better stress distribution between the implants.

\section{Financial support}

Grant number \#2014/11860-3, São Paulo research foundation (FAPESP), São Paulo, Brazil

Grant number \#208/14, Neodent, Curitiba, Paraná, Brazil

\section{Resumo}

Neste estudo foi avaliado desajuste vertical, a passividade e a distribuição de tensões após o aperto dos parafusos de diferentes próteses. Dois implantes foram usados para simular a reabilitação do espaço edêntulo da mandíbula do segundo pré-molar ao segundo molar. Quarenta próteses dentárias fixas parafusadas de três elementos com cantilever distal foram confeccionadas e separadas em quatro grupos de acordo com o método de obtenção da infraestrutura $(n=10)$ : $G 1$ = fundição convencional estrutura 
monobloco, G2 = fundição convencional seccionada e soldagem a laser, G3 = fundição convencional seccionada e soldagem com gás inerte de tungstênio (TIG) e G4 = infraestrutura obtida pelo sistema CAD I CAM (computer-aided design/computer-aided manufacturing). Os desajustes verticais com ambos os parafusos apertados e os desajustes relativos à avaliação de passividade com um parafuso apertado foram medidos com microscópio comparador óptico. Os dados foram submetidos ao teste de Shapiro-Wilk para comparação com ANOVA seguida de ajuste de Tukey com Bonferroni $(\alpha=0,05)$. A análise qualitativa da distribuição de tensões foi realizada pelo método fotoelástico. G2 $(24 \mu \mathrm{m})$ e G3 $(27 \mu \mathrm{m})$ apresentaram valores significativamente maiores que $\mathrm{G} 4(10 \mu \mathrm{m})(\mathrm{p}=0,006)$ de desajuste vertical (ambos os parafusos apertados). Os valores de desajustes nos $\mathrm{G} 1(64 \mu \mathrm{m})$ e $\mathrm{G} 3(61 \mu \mathrm{m})$, do lado não apertado, foram significativamente maiores que no $\mathrm{G} 4(32 \mu \mathrm{m})(\mathrm{p}=0,009)$. $\mathrm{G} 1$ apresentou maior tensão entre os implantes na análise fotoelástica e $\mathrm{G} 4$ apresentou menor tensão. 0 método CAD/CAM resultou em menor desajuste, maior passividade e melhor distribuição de tensões no osso. 


\section{References}

1. Perdijk FB, Meijer GJ, Bronkhorst EM, Koole R. Implants in the severely resorbed mandibles: whether or not to augment? What is the clinician's preference? Oral Maxillofac Surg 2011;15:225-31.

2. Ozan 0, Kurtulmus-Yilmaz S. Biomechanical comparison of cifferent implant inclinations and cantilever lengths in all-on-4 treatment concept by three-dimensional finite element analysis. Int J Oral Maxillofac Implants 2018;33:64-71.

3. Romanos GE, Gupta B, Eckert SE. Distal cantilevers and implant dentistry. Int J Oral Maxillofac Implants 2012;27:1131-6.

4. Freitas da Silva EV, Dos Santos DM, Sonego MV, de Luna Gomes JM, Pellizzer EP, Goiato MC. Does the presence of a cantilever influence the survival and success of partial implant-supported dental prostheses? Systematic review and meta-analysis. Int J Oral Maxillofac Implant 2018;33:815-23.

5. Romanos GE, Gupta B, Gaertner K, Nentwig GH. Distal cantilever in full-arch prostheses and immediate loading: A retrospective clinical study. Int J Oral Maxillofac Implants 2014;29:427-31.

6. Wu MJ, Wang XJ, Zou LD, Xu WH, Zhang XH. Evaluation of the therapeutic efficiency of mandibular anterior implant-supported fixed bridges with cantilevers. Chin Med J (Engl) 2013;126:466569.

7. Suedam V, Moretti Neto RT, Sousa EA, Rubo JH. Effect of cantilever length and alloy framework on the stress distribution in peri-implant area of cantilevered implant-supported fixed partial dentures. J Appl Oral Sci 2016;24:114-20.

8. Al-Meraikhi H, Yilmaz B, McGlumphy E, Brantley W, Johnston WM. In vitro fit of CAD-CAM complete arch screw-retained titanium and zirconia implant prostheses fabricated on 4 implants. J Prosthet Dent 2018;119:409-16.

9. Jemt T. Failures and complications in 391 consecutively inserted fixed prostheses supported by Branemark implants in edentulous jaws: A study of treatment from the time of prosthesis placement to the first annual checkup. Int J Oral Maxillofac Implants 1991;6:270-76.

10. Jemt T, Book K. Prosthetic misfit and marginal bone loss in edentulous implant patients. Int J Oral Maxillofac Implants 1996;11:620-25.

11. Simamoto Júnior PC, Resende Novais V, Rodrigues Machado A, Soares CJ, Araújo Raposo LH. Effect of joint design and welding type on the flexural strength and weld penetration of Ti-6Al-4V alloy bars. J Prosthet Dent 2015;113:467-74.

12. Lencioni KA, Macedo AP, Silveira Rodrigues RC, Ribeiro RF, Almeida RP. Photoelastic comparison of as-cast and laser-welded implant frameworks. J Prosthet Dent 2015;114:652-9.

13. Spazzin AO, Bacchi A, Trevisani A, Farina AP, Dos Santos MB. Fit analysis of different framework fabrication techniques for implant-supported partial prostheses. Int J Prosthodont 2016;29:351-3.

14. Pellizzer EP, Mello CC, Gomes JML, Santiago Junior JF, Lemos CAA, Verri FR. Vertical and misfit analysis of 3-unit FDP fabricated with different techniques and CAD/CAM Systems. Braz Dent J 2018;29:342-46.

15. Hart CN, Wilson PR. Evaluation of welded titanium joints used with cantilevered implantsupported prostheses. J Prosthet Dent 2006;96:25-32.

16. Al Jabbari YS, Koutsoukis T, Barmpagadaki X, El-Danaf EA, Fournelle RA, Zinelis S. Effect of $\mathrm{Nd}: \mathrm{YAG}$ laser parameters on the penetration depth of a representative $\mathrm{Ni}-\mathrm{Cr}$ dental casting alloy. Lasers Med Sci 2015;30:909-14.

17. Yannikakis S, Prombonas A. Improving the fit of implant prosthetics: an in vitro study. Int J Oral Maxillofac Implants 2013;28:126-34.

18. Menini $M$, Setti $P$, Pera F, Pera $P$, Pesce P. Accuracy of multi- unit implant impression: Traditional techniques versus a digital procedure. Clin Oral Investig 2018;22:1253-62.

19. da Cunha Fontoura D, de Magalhães Barros V, de Magalhães CS, Vaz RR, Moreira AN. Evaluation of vertical misfit of CAD/CAM implant-supported titanium and zirconia frameworks. Int J Oral Maxillofac Implants 2018;33:1027-32.

20. Kim KB, Kim WC, Kim JH. Three-dimensional evaluation of gaps associated with fixed dental prostheses fabricates with new technologies. J Prosthet Dent 2014;112:1432-6.

21. Berejuk HM, Shimizu RH, de Mattias Sartori IA, Valgas L, Tiossi R. Vertical microgap and passivity of fit of three-unit implant-supported frameworks fabricated using different techniques. Int J Oral Maxillofac Implants 2014;29:1064-70.

22. Zaparolli D, Peixoto RF, Pupim D, Macedo AP, Toniollo MB, Mattos MDGC. Photoelastic analysis of mandibular full-arch implant-supported fixed dentures made with different bar materials and manufacturing techniques. Mater Sci Eng C Mater Biol Appl 2017;1;81:144-7. 
23. Peixoto RF, Macedo AP, Martinelli J, Faria ACL, Tiossi R, Ribeiro RF, de Mattos MDGC. A digital image correlation analysis of strain generated by 3-unit implant-supported fixed dental prosthesis: an in vitro study. Implant Dent 2017;26(4):567-73.

24. Peixoto RF, Tonin BSH, Martinelli J, Macedo AP, de Mattos MDGC. In vitro digital image correlation analysis of the strain transferred by screw-retained fixed partial dentures supported by short and conventional implants. J Mech Behav Biomed Mater 2020;103:103556.

25. De Castro GC, de Araújo CA, Mesquita MF, Consani RL, Nóbilo MAA. Stress distribution in $\mathrm{Co}-\mathrm{Cr}$ implant frameworks after laser or TIG welding. Braz Dent J 2013;24:147-51.

26. Rabitz GK, Berson R, Caputo AA, Franklin RJ, Del Fierro DB. Load-induced stress in photoelastic primary canines with facial restorations. J Dent Child 2006;73: 170-4.

27. Nascimento JFM, Aguiar-Júnior FA, Nogueira TE, Rodrigues RCS, Leles CR. Photoelastic Stress Distribution Produced by Different Retention Systems for a Single-Implant Mandibular Overdenture. J Prosthodont 2015;24:538-42.

28. Katsoulis J, Takeichi T, Sol Gaviria A, Peter L, Katsoulis K. Misfit of implant prostheses and its impact on clinical outcomes. Definition, assessment and a systematic review of the literature. Eur J Oral Implantol 2017;10 Suppl 1:121-38.

29. Cao XJ, Jahazi M, Immarigeon JP, Walace $W$. A review of laser welding techniques for magnesium alloys. Journal of Materials Processing Technology 171, 188-204.

30. Tiossi R, Falcão-Filho $H$, Aguiar Júnior FA, Rodrigues RC, Mattos Mda G, Ribeiro RF. Modified section method for laser-welding of ill-fitting cp $\mathrm{Ti}$ and $\mathrm{Ni}-\mathrm{Cr}$ alloy one-piece cast implant-supported frameworks. J Oral Rehabil 2010;37:359-63.

31. Rodrigues SA, Presotto AGC, Barão VAR, Consani RLX, Nóbilo MAA, Mesquita MF. The role of welding techniques in the biomechanical behavior of implant-supported prostheses. Mater Sci Eng $C$ Mater Biol Appl 2017;78:435-42.

32. Matsumoto W, Beraldo PP, de Almeida RP, Macedo AP, Kubata BR, Hotta TH. Evaluation of Marginal Misfit of Metal Frameworks Welded by Gas-Torch, Laser, and Tungsten Inert Gas Methods. Int J Dent 2018;30;2018:9828929.

33. Barbi FC, Camarini ET, Silva RS, Endo EH, Pereira JR. Comparative analysis of different joining techniques to improve the passive fit of cobalt-chromium superstructures. J Prosthet Dent 2012 Dec;108(6):377-85.

34. Gomes JML, Moraes SLD, Lemos CAA, Cruz RS, Oliveira HFFE, Pellizzer EP. Systematic review and meta-analysis of welding procedures in one-piece cast implant-supported frameworks. Braz Oral Res 2019;25;33:e110

35. Perveen A, Molardi C, Fornaini C. Applications of Laser Welding in Dentistry: A State-of-the-Art Review. Micromachines (Basel). 2018;9(5):209.

36. Talic $R$, Alfadda SA. Internal adaptation of implant-supported, polymer-infused ceramic crowns fabricated by two CAD/CAM systems. J Prosthodont 2018;27:868-876.

37. Uribarri A. Bilbao-Uriarte $E_{1}$ Segurola $A$, Ugarte $D$, Verdugo F. Marginal and internal fit of CAD/CAM frameworks in multiple implant-supported restorations: Scanning and milling error analysis. Clin Implant Dent Relat Res 2019;21:1062-72.

38. De Freitas BN, Tonin BSH, Macedo AP, Dos Santos TMP, De Mattos MDGC, Hotta TH, Matsumoto W. Adaptation accuracy of milled lithium disilicate crowns: A 2D and 3D microCT analysis. J Esthet Restor Dent 2020;10.1111/jerd.12574.

39. Ender A, Mehl A. Influence of scanning strategies on the accuracy of digital intraoral scanning systems. Int J Comput Dent 2013;16:11-21.

40. Katsoulis J, Mericske-Stern R, Enkling N, Katsoulis K, Blatz MB. In vitro precision of fit of computer-aided designed and computer-aided manufactured titanium screw-retained fixed dental prostheses before and after ceramic veneering. Clin Oral Implants Res. 2015;26(1):44-9.

41. Bra ${ }^{\circ}$ nemark PI. Osseointegration and its experimental background. J Prosthet Dent 1983;50:399-410.

42. Celik G, Uludag B. Photoelastic stress analysis of various retention mechanisms on 3-implantretained mandibular overdentures. J Prosthet Dent. 2007;97(4):229-35.

43. Wyatt CC, Zarb GA. Bone level changes proximal to oral implants supporting fixed partial prostheses. Clin Oral Implants Res. 2002;13(2):162-8. 